\title{
CONGENITAL TRICUSPID ATRESIA
}

\author{
BY \\ ROY ASTLEY, J. S. OLDHAM, AND CLIFFORD PARSONS
}

From the Children's Hospital, Birmingham

Received December 2, 1952

Many papers have been written on the diagnosis and prognosis of tricuspid atresia. Differences between various descriptions, especially in papers on X-ray features, may be explained partly by the rarity of the condition and partly by the effects produced by other complicating anomalies. Tricuspid atresia is responsible for only about 5 per cent of all cyanotic heart disease in infancy, and many patients die in the first few months of life. Consequently it is unlikely that any one centre will quickly collect a large series of cases and it may be of value to describe our findings in 15 patients with tricuspid atresia and one with congenital tricuspid stenosis, We are grateful to colleagues who have referred these patients to us for investigation.

As advocated by Edwards and Burchell (1949), we have attempted to classify our cases into those with and those without associated transposition of the great vessels, and have subdivided these two groups according to the presence or absence of pulmonary (or sub-pulmonary) stenosis. The importance of recognizing these associated abnormalities early has been stressed by Kroop (1951), who points out that a child who has tricuspid atresia, without transposition but with pulmonary stenosis, has a 66 per cent chance of dying in infancy; and that it is the child with precisely this combination of defects who best responds to operative treatment. Gasul et al. (1949) have given practical support to this view by obtaining successful anastomosis, even in very young infants, by using Potts's modification of the Blalock-Taussig operation.

The abnormalities that have been disclosed in our cases are summarized in Table I. Dr. H. S. Baar has kindly provided us with necropsy reports. Although anatomical records of similar accuracy cannot be obtained in the living subject, angiocardiography allows the atrial septal defect to be seen clearly and we have assumed transposition to be present when the pulmonary artery fills early and directly from the left ventricle. We have not accepted inadequate and/or delayed filling of the pulmonary artery as evidence of pulmonary stenosis, for this also occurs in the absence of stenosis when the pulmonary artery originates from a vestigial right ventricle. The methods have provided sufficient information to allow us to divide our cases into 7 with transposition ( 3 of whom had pulmonary stenosis) and 9 without transposition ( 3 with pulmonary stenosis, 3 with normal pulmonary arteries, and 3 not determined). We observed no example of pulmonary atresia and the ductus may well have been patent in more cases than we recognized. One child (M.A.) had an extraordinary heart, which will be described in detail in a separate paper; the vestigial right ventricle emptied into a hypoplastic pulmonary artery and was in communication not only with a hypertrophied left ventricle but also with a third ventricular chamber which lay under the skin of the abdominal wall.

\section{Clinical Findings}

Taussig (1936 and 1947) has given a succinct account of the symptoms and signs of tricuspid atresia. We can add nothing to her descriptions and therefore confine our comments to certain more controversial features.

Cyanosis was early apparent (Table II) and was sometimes present at birth, but we have been unable to confirm the statement by Gasul et al. (1950) that early and intense cyanosis suggests 
TABLE I

Nature of ANatomical Defect

\begin{tabular}{|c|c|c|c|c|c|c|}
\hline & Patient & $\begin{array}{l}\text { Evi- } \\
\text { dence }\end{array}$ & Right ventricle & $\begin{array}{c}\text { Left } \\
\text { ventricle }\end{array}$ & Pulmonary artery & Aorta \\
\hline (a) & $\begin{array}{l}\text { D.C. } \\
\text { R.o'S. } \\
\text { C.L. }\end{array}$ & $\begin{array}{l}\mathbf{N} \\
\mathbf{N} \\
\mathbf{A}\end{array}$ & $\begin{array}{l}\text { Vestigial } \\
\text { Small } \\
\text { Vestigial, fills late }\end{array}$ & $\begin{array}{l}\text { Transpo } \\
\text { Large } \\
\text { Large }\end{array}$ & \begin{tabular}{|ll} 
sition & \\
From LV. & Stenosed \\
From RV. & Stenosed \\
From LV. & Poor flow
\end{tabular} & $\begin{array}{ll}\text { From RV. } & \text { Large } \\
\text { From RV. } & \text { PDA. } \\
\text { From LV } & \end{array}$ \\
\hline (b) & $\begin{array}{l}\text { C.H. } \\
\text { P.T. } \\
\text { B.S. } \\
\text { L.B. }\end{array}$ & $\begin{array}{l}\mathbf{A} \\
\mathbf{N} \\
\mathbf{A} \\
\mathbf{A}\end{array}$ & $\begin{array}{l}\text { Not seen } \\
\text { Small } \\
\text { Vestigial, fills late } \\
\text { Vestigial, fills late }\end{array}$ & Large & $\begin{array}{ll}\text { From LV. } & \text { Fills early } \\
\text { From LV } & \\
\text { From LV. } & \text { Good flow } \\
\text { From LV } & \end{array}$ & $\begin{array}{ll}\text { From RV. } & \text { Fills late } \\
\text { From RV } & \\
\text { From RV. } & \text { Fills late } \\
\text { From RV } & \end{array}$ \\
\hline (a) & $\begin{array}{l}\text { M.A. } \\
\text { M.O'N. } \\
\text { P.D. }\end{array}$ & $\begin{array}{l}\mathbf{N} \\
\mathbf{N} \\
\mathbf{N}\end{array}$ & $\begin{array}{l}\text { With } \\
\text { Vestigial. Subumbilical ex- } \\
\text { tension } \\
\text { Vestigial } \\
\text { Small, tricuspid stenosis }\end{array}$ & $\begin{array}{l}\text { out Trans } \\
\text { Large } \\
\text { Large } \\
\text { Intact } \\
\text { VS }\end{array}$ & \begin{tabular}{|ll} 
position & \\
From RV. & Stenosed \\
& \\
From RV. & Stenosed \\
From RV. & Stenosed
\end{tabular} & $\begin{array}{l}\text { From LV } \\
\text { From LV } \\
\text { From LV }\end{array}$ \\
\hline (b) & $\begin{array}{l}\text { J.O. } \\
\text { J.S. } \\
\text { J.F. }\end{array}$ & $\begin{array}{l}\mathbf{N} \\
\mathbf{N} \\
\mathbf{N}\end{array}$ & $\begin{array}{l}\text { Vestigial } \\
\text { Vestigial } \\
\text { Small }\end{array}$ & $\begin{array}{l}\text { Large } \\
\text { Normal } \\
\text { Large }\end{array}$ & $\begin{array}{l}\text { From RV } \\
\text { From RV } \\
\text { From RV }\end{array}$ & $\begin{array}{l}\text { From LV. PDA. } \\
\text { From LV } \\
\text { From LV }\end{array}$ \\
\hline (c) & $\begin{array}{l}\text { J.H. } \\
\text { D.D. } \\
\text { P.M. }\end{array}$ & $\begin{array}{l}\text { A } \\
\text { A } \\
\mathbf{A}\end{array}$ & $\begin{array}{l}\text { Not seen } \\
\text { Not seen } \\
\text { Not seen }\end{array}$ & & $\begin{array}{l}\text { ? From RV. Poor flow, } \\
\text { fills late Poor flow } \\
\text { ? Origin. Pow, } \\
\text { ? From RV. Poor flow, } \\
\text { fills late } \\
\text { ? Large bronchial arteries }\end{array}$ & $\begin{array}{l}\text { From LV } \\
\text { From LV } \\
\text { From LV }\end{array}$ \\
\hline
\end{tabular}

Abbreviations: $\mathrm{LV}, \mathrm{RV}=\mathrm{left}$ and right ventricles. $\mathrm{VS}=$ ventricular septum. $\mathrm{PDA}=$ patent ductus arteriosus. $\mathbf{N}=$ Necropsy. A=Angiocardiogram.

All patients have an atrial septal defect, usually with enlargement of both atria. All except the child with tricuspid stenosis have a ventricular septal defect.

tricuspid atresia without transposition. In fact transposition was absent in the only infant who was never cyanosed: she died of heart failure at the age of five weeks, but at no time was she blue. Children who survived long enough developed finger and toe clubbing. Moderate polycythæmia was common. Four children (C.L., M.O'N., J.F., and D.D.) had spontaneous attacks of unconsciousness; three of these had radiological evidence of pulmonary oligæmia and one (C.L.) would draw himself into the knee-elbow position during attacks of dyspnœa. Only one child squatted; his lung vessels were congested. Dyspnœa was almost always a feature and, in those who were old enough to walk, exercise tolerance was severely limited.

Congestion and prominent pulsation in the neck veins was a valuable diagnostic sign, but hepatic engorgement was sometimes more readily recognized in infants. When considering differential diagnosis it is well to remember that striking pulsation of the neck veins may occur in patients with pulmonary stenosis and an intact interventricular septum. Peripheral œdema was recorded three times and splenic enlargement twice.

Heart Size. We failed to confirm the impression (Gasul et al., 1950) that infants with transposition have bigger hearts than those without transposition; indeed, we were unable to discover any method by which to distinguish clinically between patients with and without transposition. Nor were we able to determine from history and physical signs whether children had pulmonary plethora or oligæmia. We did notice that by our clinical methods we tended to underestimate the size of the heart. While murmurs were usual, they were not invariable. They were 
TABLE II

Main Clinical Features

\begin{tabular}{|c|c|c|c|c|c|c|c|c|c|}
\hline Classification & Patient & $\operatorname{Sex}$ & $\begin{array}{c}\text { Diagnosis } \\
\text { at age }\end{array}$ & $\begin{array}{l}\text { Con- } \\
\text { firmed } \\
\text { by }\end{array}$ & $\begin{array}{c}\text { First } \\
\text { cyanosed }\end{array}$ & $\begin{array}{l}\text { Neck } \\
\text { veins }\end{array}$ & $\begin{array}{c}\text { Lung } \\
\text { fields } \\
\text { (X-ray) }\end{array}$ & $\begin{array}{c}\text { Heart } \\
\text { size } \\
\text { (clinical) }\end{array}$ & $\begin{array}{l}\text { Electrical } \\
\text { axis }\end{array}$ \\
\hline (a) Pulmonary stenosis & $\begin{array}{l}\text { D.C. } \\
\text { R.O'S. } \\
\text { C.L. }\end{array}$ & $\begin{array}{l}\mathbf{M} \\
\mathbf{F} \\
\mathbf{F}\end{array}$ & $\begin{array}{l}\quad \text { With } \\
8 \text { mo. } \\
2 \text { mo. } \\
3\end{array}$ & $\begin{array}{c}\text { Transpositi } \\
\text { N } \\
\text { N } \\
\text { A }\end{array}$ & $\begin{array}{l}\text { on } \\
\text { Birth } \\
\text { Birth } \\
4 \text { mo. }\end{array}$ & $\begin{array}{l}+ \\
+ \\
+\end{array}$ & $\begin{array}{l}\text { Oligæmic } \\
\text { Oligæmic } \\
\text { Oligæmic }\end{array}$ & $\begin{array}{c}\text { Normal } \\
+ \\
+\end{array}$ & $\begin{array}{l}\bar{L} \\
\mathrm{~L}\end{array}$ \\
\hline (b) No stenosis & $\begin{array}{l}\text { C.H. } \\
\text { P.T. } \\
\text { B.S. } \\
\text { L.B. }\end{array}$ & $\begin{array}{l}\mathbf{F} \\
\mathbf{M} \\
\mathbf{M} \\
\mathbf{F}\end{array}$ & \begin{tabular}{|c|}
$10^{*}$ \\
2 \\
6 \\
8
\end{tabular} & $\begin{array}{l}\mathbf{A} \\
\mathbf{N} \\
\mathbf{A} \\
\mathbf{A}\end{array}$ & $\begin{array}{l}3 \mathrm{mo} . \\
3 \mathrm{mo} . \\
3 \mathrm{mo} . \\
3 \mathrm{mo} .\end{array}$ & $\begin{array}{c}- \\
\text { Normal } \\
\text { Normal } \\
+\end{array}$ & $\begin{array}{l}\text { Normal } \\
\text { Congested } \\
\text { Normal } \\
\text { Congested }\end{array}$ & $\begin{array}{c}\text { Normal } \\
+ \\
\text { Normal } \\
+\end{array}$ & $\begin{array}{l}\mathrm{L} \\
\mathbf{R} \\
\mathbf{L} \\
\mathbf{L}\end{array}$ \\
\hline & & & With & out Transp & osition & & & & \\
\hline (a) Pulmonary stenosis & $\begin{array}{l}\text { M.A. } \\
\text { M.O'N. } \\
\text { P.D. } \dagger \\
\end{array}$ & $\begin{array}{l}\mathbf{F} \\
\mathbf{F} \\
\mathbf{M}\end{array}$ & $\begin{array}{r}18 \mathrm{mo} . \\
12 \mathrm{mo} . \\
1 \mathrm{wk} .\end{array}$ & $\begin{array}{l}\mathbf{N} \\
\mathbf{N} \\
\mathbf{N}\end{array}$ & $\begin{array}{l}1 \text { mo. } \\
6 \text { mo. } \\
3 \text { days }\end{array}$ & \pm & $\begin{array}{l}\text { Oligæmic } \\
\text { Oligæmic } \\
\text { Oligæmic }\end{array}$ & $\begin{array}{l}+ \\
+ \\
+\end{array}$ & $\begin{array}{l}\mathrm{L} \\
\mathrm{L} \\
-\end{array}$ \\
\hline (b) No stenosis & $\begin{array}{l}\text { J.O. } \\
\text { J.S. } \\
\text { J.F. }\end{array}$ & $\begin{array}{l}\mathbf{F} \\
\mathbf{F} \\
\mathbf{M}\end{array}$ & $\begin{array}{l}1 \mathrm{mo} . \\
2 \mathrm{mo} . \\
2 \mathrm{mo} .\end{array}$ & $\begin{array}{l}\mathbf{N} \\
\mathbf{N} \\
\mathbf{N}\end{array}$ & $\begin{array}{l}\text { Not blue } \\
1 \text { mo. } \\
\text { Birth }\end{array}$ & $\begin{array}{c}+ \\
\text { Normal } \\
+\end{array}$ & $\begin{array}{l}\text { Congested } \\
\text { Oligæmic } \\
\text { Normal }\end{array}$ & $\begin{array}{c}+ \\
\text { Normal } \\
+\end{array}$ & 二 \\
\hline (c) Undetermined & $\begin{array}{l}\text { J.H. } \\
\text { D.D. } \\
\text { P.M. }\end{array}$ & $\begin{array}{l}\mathbf{M} \\
\mathbf{M} \\
\mathbf{M}\end{array}$ & $\begin{array}{l}11 \\
18 \mathrm{mo} . \\
4\end{array}$ & $\begin{array}{l}\mathbf{A} \\
\mathbf{A} \\
\mathbf{A}\end{array}$ & $\begin{array}{l}10 \text { days } \\
2 \text { mo. } \\
\text { Birth }\end{array}$ & $\begin{array}{l}+ \\
+ \\
+\end{array}$ & $\begin{array}{l}\text { Oligæmic } \\
\text { Oligæmic } \\
\text { Oligæmic }\end{array}$ & $\begin{array}{l}+ \\
+ \\
+\end{array}$ & $\begin{array}{l}\text { L } \\
\text { L } \\
\text { L }\end{array}$ \\
\hline
\end{tabular}

* Died one year later: no necropsy. † Tricuspid stenosis. N=Necropsy. A=Angiocardiogram.

commonly systolic, rough, best heard in the third intercostal space close to the sternum, and sometimes audible at the back of the chest between the scapulæ. Our attempts to gain useful information from an analysis of the second sound at the base of the heart were unsuccessful. Blood pressure readings were within the normal range.

\section{ELECTROCARDIOGRAPHY}

Electrocardiograms were taken in 11 patients (Fig. 1) and we agree with other writers that left ventricular preponderance or marked left axis deviation in cyanotic heart disease is almost diagnostic

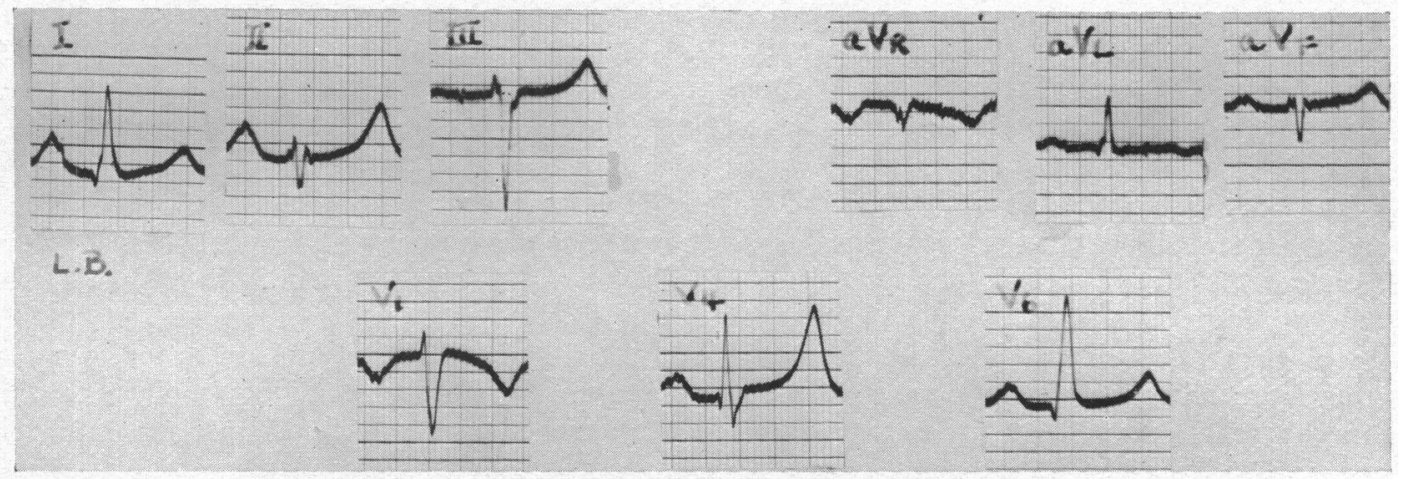

Fig. 1.-Typical electrocardiogram showing left ventricular preponderance as was seen in all the cases except one. 
of tricuspid atresia with a rudimentary right ventricle. One of our patients had left bundle branch block, which is unusual.

It is widely recognized that left axis deviation and cyanosis may occur in other conditions, and we have seen the combination in Eisenmenger's complex, complete transposition of the great vessels, single ventricle with persistent truncus arteriosus communis, and in a child whose cyanosis was due to methæmoglobinæmia. Gasul et al. (1950) have recorded similar findings in Ebstein's disease and in patients whose great veins open into the left atrium; Donzelot et al. (1950) mention a case of infantile coarctation with cyanosis and left axis deviation.

Records of right ventricular preponderance or right axis deviation from patients with tricuspid atresia are less common (Kroop and Grishman, 1950). One of our patients (P.T.) showed this phenomenon in a minor degree (Fig. 2): unfortunately no chest leads were obtained. The child

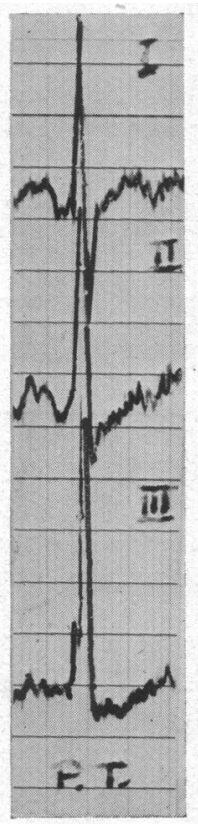

Fig. 2.-An unusual electrocardiogram showing the absence of left axis deviation, but unfortunately, chest leads were not available. died suddenly during right heart catheterization and the diagnosis of tricuspid atresia with rudimentary right ventricle and transposition of the great vessels was confirmed at necropsy. No satisfactory explanation could be advanced to account for the electrocardiographic findings nor for the unexpected death.

\section{RADIOLOGY}

The X-ray picture of tricuspid atresia is said to be characteristic, and has been described as follows.

In the frontal projection. (1) Diminished pulmonary vascular markings (except when there is an associated transposition of the great vessels).

(2) Concavity of the left middle segment.

(3) Prominent left lower segment-“long and convex" (Eek, 1949); "well rounded" (Brown, 1950); " unusual . . . a blunt and false apex high above the diaphragm" (Wittenborg et al., 1951).

In the left anterior oblique position. (1) A prominent posterior border, requiring considerable rotation to clear the spine (a large left ventricle).

(2) Little or no forward projection (small or absent right ventricle).

Various other features have been added to this generally accepted description of the characteristic pattern. For example, Taussig (1947) mentions that the shadow of the great vessels is narrow and does not increase in width when the patient is rotated into the left oblique position. She also describes dilatation of the superior vena cava as a sign evident in early infancy, and increased lung vascularity when there is associated transposition. In the frontal projection Gasul et al. (1950) note that the border of the heart extends only slightly to the right of the spine; Brown (1950) says that the right border has an exaggerated convexity, but others (Cooley et al., 1950; Wittenborg et al., 1951) speak of diminished convexity or even concavity. Eek (1949) points out that both atria are large, and Snow (1952) talks of paradoxical pulsation of the anterior and posterior borders when the heart is viewed in the left anterior oblique position.

Wittenborg et al. (1951) found that only 2 of their 11 cases had the " characteristic " radiological appearances, and suggested that right atrial enlargement, due to smallness of the atrial septal defect, often obscured the hypoplasia of the right ventricle. Most of their cases were indistinguishable from Fallot's tetralogy.

We also have felt dissatisfied with the usually accepted $\mathrm{X}$-ray features and, in order to try to discover more reliable diagnostic signs, we have compared the features outlined in the preceding paragraphs with those seen in our patients (Fig. 3). The cases divide themselves into two distinct groups from the radiologist's point of view, according to the degree of vascularity of the lung fields. 

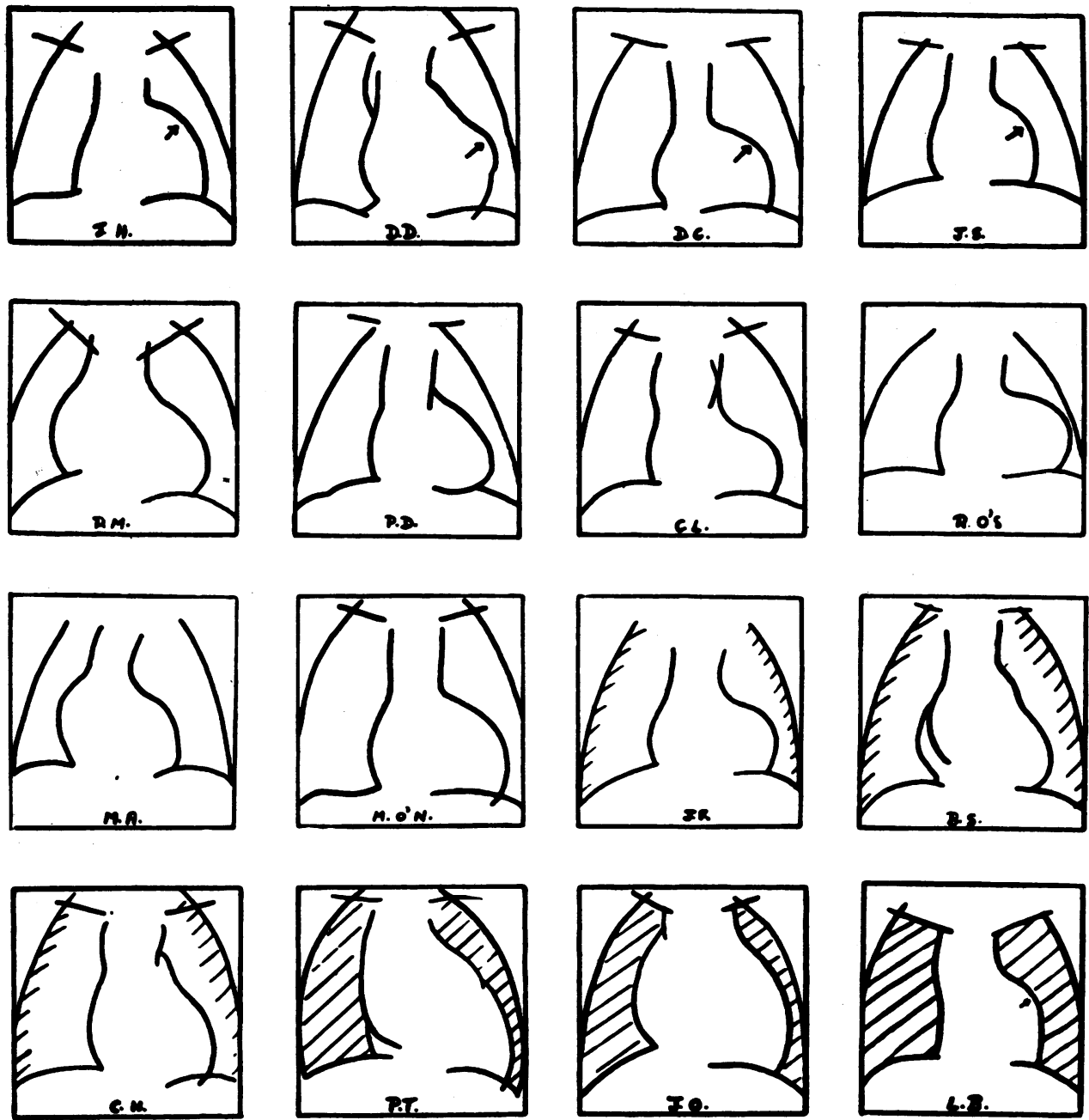

Fig. 3. - The cardiac silhouettes of 15 children with tricuspid atresia and 1 child with tricuspid stenosis. (Clear lungs indicate pulmonary oligæmia; partial shading means normal vascularity and complete shading pulmonary plethora.)

\section{Group 1. Reduced Pulmonary Vascularity (10 Cases, 3 with Transposition)}

(A) Frontal Projection

The left middle segment was concave in 9 and flat in 1 child and probably indicates either a misplaced (i.e. transposed) pulmonary artery or one carrying little blood. The latter may occur when there is pulmonary stenosis or sometimes when an artery of -normal size originates from the rudimentary right ventricle.

The left lower segment was unusual in shape in 5 of the 10 children. Its lower part ran a long and vertical course and its upper part was remarkably prominent and angulated. This gave the heart a somewhat square shape (Fig. 4). In the other 5 children there was a tendency to the same configuration although in two it was much less definite.

The shadow of the great vessels was narrow in 7 cases, but only once to a striking degree. This child (D.C.) had complete transposition of the great vessels.

The right border of the heart extended only slightly to the right of the spine in 7 patients. It sometimes showed a flatter curve than usual. 


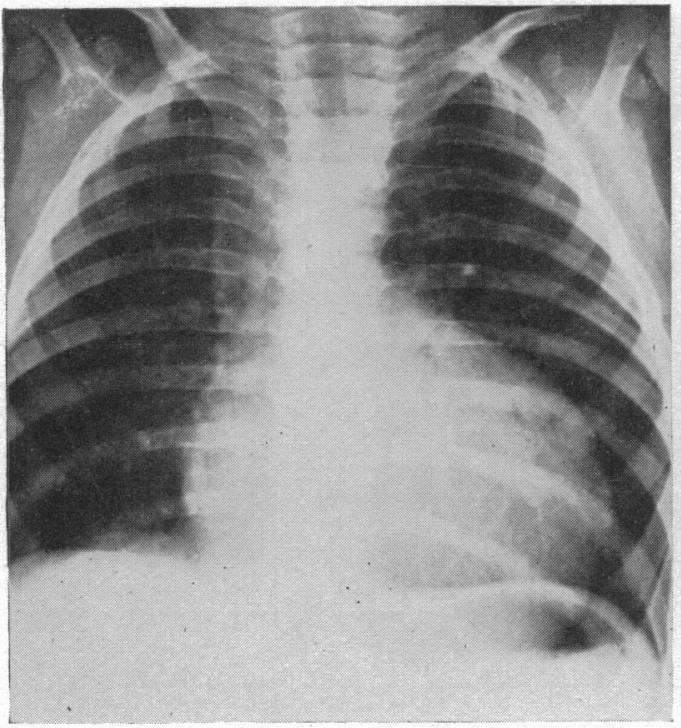

A

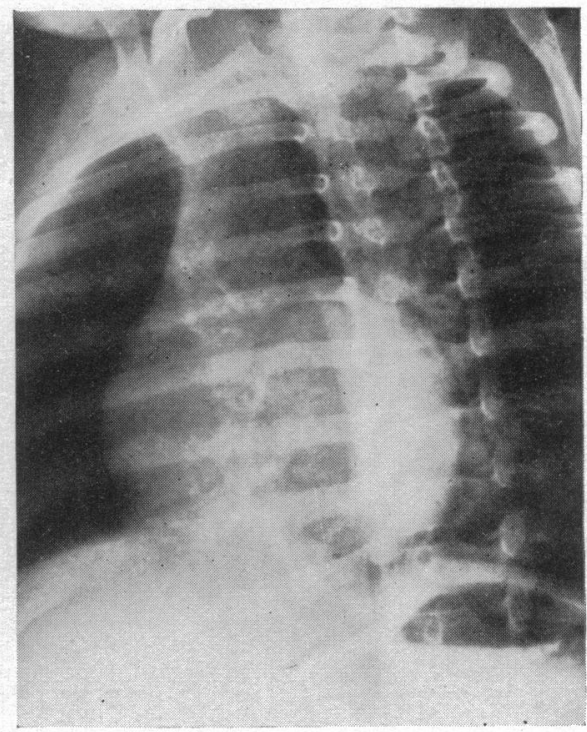

B

FIG. 4.-(A) The " square" heart shape in the frontal view. There is a prominence in the upper part of the lower segment of the left border, below a concave pulmonary segment. Other features in this child are pulmonary oligæmia, a rather narrow great vessel shadow and the slight cardiac extension to the right of the spine. (B) The "square" appearance in the left oblique view. The same child as in Fig. $4 \mathrm{~A}$. Both the left atrial and the left ventricular segments of the posterior border are prominent. The anterior border is not prominent.

\section{(B) Left Anterior Oblique Projection}

The prominence of the posterior border, not only in its lower (left ventricular) segment but also higher up towards the tracheal bifurcation in the left atrial segment, made the heart somewhat square, with an appearance akin to that noted in the frontal projection (Fig. 4 and 5).

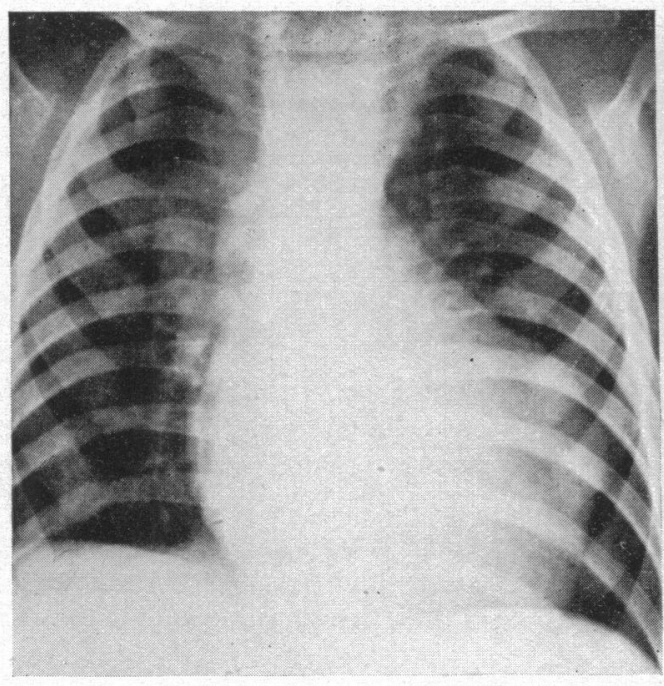

A

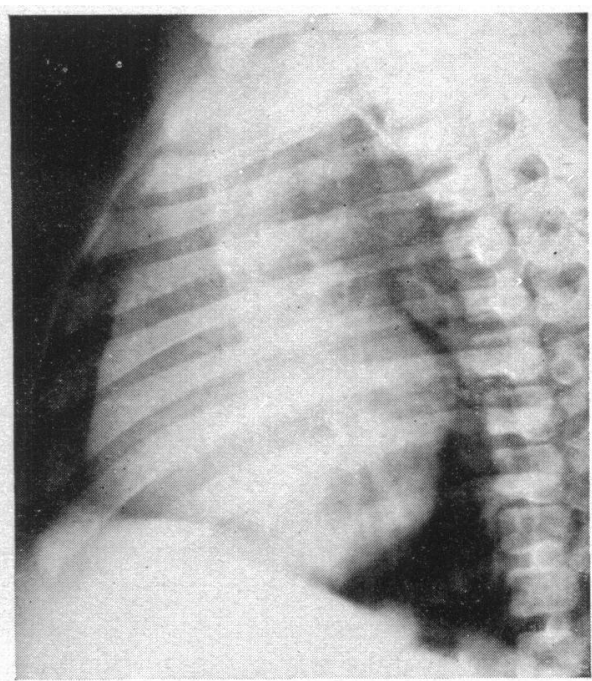

B

FIG. 5.-(A) Another example of the "square" shape. In this child the prominence on the left border constitutes a separate segment. (B) The "square" appearance in the left oblique view, corresponding to Fig. $5 \mathrm{~A}$. The left atrial and left ventricular prominences posteriorly are distinct. 
The projection of the anterior border varied from flat to normal but was never increased.

As we have not looked specifically for paradoxical pulsation in most of these children we cannot here assess its importance.

(C) Right Anterior Oblique Projection

A barium swallow gave no indication of left atrial enlargement in the four children examined.

Group II. Normal or InCreased Pulmonary Vascularity (6 Cases; 4 with

(A) Frontal Projection

\section{TRANSPOSITION)}

The left middle segment was sometimes concave, sometimes prominent.

In the left lower segment, only one child's heart had the square shape seen in Group I. Two hearts were not enlarged and one of these was almost normal in shape; another was large and globular with no specific features to suggest a diagnosis.

Narrowing of the shadow of the great vessels was observed once; the child had a right-sided aortic arch.

Four of the six patients showed only slight extension of the right border of the heart shadow to the right of the spine. In one child this border was slightly concave.

On two occasions the left atrium could be seen through the heart shadow as a rounded area of increased opacity.

\section{(B) Left Anterior Oblique Projection}

Posterior border. The square shape described in Group I was observed only once, in the child already mentioned who had a similar appearance in the frontal view. In another child there was gross backwards and downwards bulging of the left ventricular segment. Another child had no apparent left ventricular enlargement.

The child with the square heart presented a flat anterior border. Two children had a forward bulging of the upper part of the border, probably right atrial in origin. In one of these there was a notch anteriorly just above the diaphragm, presumably at the point of junction with a hypoplastic right ventricle.

\section{(C) Right Anterior Oblique Projection}

Five children were examined. The œsophagus was displaced by considerable left atrial enlargement in one child; there was slight enlargement in two, possibly slight enlargement in one and no enlargement in the fifth.

\section{Discussion of RADiological Findings}

Although the lung fields are usually oligæmic, clearly this is not an essential nor even a characteristic feature of the X-ray appearance. And when the lungs are congested it does not necessarily mean that there is associated transposition of the great vessels; we have seen congested lungs in the absence of transposition, and oligæmia in its presence.

In view of Wittenborg's (1951) difficulty of distinguishing tricuspid atresia from Fallot's tetralogy, we have particularly compared our findings in the present series with those of 41 children with the latter condition.

Frontal projection. The most striking differential feature in the frontal projection appears to be the shape of the left heart border. In tricuspid atresia, concavity of the pulmonary segment, together with prominence in the upper part of the left lower segment and a vertical border below this, can give a square shape to the heart that we have not seen convincingly demonstrated in any other condition. Amongst the 41 cases of Fallot's tetralogy only three had any suggestion of this configuration and in none was it definite. 
Most of the children showed only slight cardiac extension to the right of the spine in the frontal position. But as 13 of the 41 with Fallot's tetralogy also showed minimal projection, we cannot regard this sign by itself as an indication of a small right ventricle. Nevertheless, when associated with a suggestive appearance of the left heart border, its presence increases the probability of the diagnosis.

In the frontal projection, various other signs, sometimes absent, may be accepted as similar corroborative evidence although they do not of themselves have great diagnostic value. These features include narrowness of the vascular pedicle and a flat or concave lower right heart border.

Left anterior oblique view. In this position, 17 of the 41 children with right ventricular hypertrophy due to Fallot's tetralogy had an X-ray appearance that exactly fitted the usually accepted description of tricuspid atresia, i.e. there was slight or no anterior cardiac projection but considerable posterior bulging. Consequently we feel that we cannot accept this appearance as evidence of a hypoplastic right ventricle. We have found as a more reliable and characteristic feature of tricuspid atresia a moderate posterior projection that involves not only the lower (left ventricular) segment but also the upper (left atrial) part of the posterior border. The segments may be clearly separated by a groove and the resultant appearance is a square shape somewhat akin to that presented in the frontal view. In a few children really gross bulging of the left ventricular segment may make the left atrial prominence less obvious, with loss of the "square" shape; but the posterior bulge of the heart then becomes directed backwards and downwards, in contrast to the purely posterior bulge of the displaced and rotated left ventricle in Fallot's tetralogy.

Tricuspid atresia is excluded if, in this position, the interventricular groove can be seen in its normal position. Considerable prominence of the anterior border excludes tricuspid atresia, but a normal amount of forward projection, or even exaggerated prominence, providing it is confined to the upper (right atrial) segment, is not inconsistent with the diagnosis. A flat anterior border, a notch anteriorly just above the diaphragm, or paradoxical pulsation as described by Snow (1952) are additional corroborative signs of tricuspid atresia.

Right anterior oblique view. We observed left atrial enlargement, detectable by barium swallow, only in children not presenting the square shape and only in those with normal or increased pulmonary vascularity. Sometimes the enlarged chamber was more evident in the frontal projection as an opacity seen through the heart. Although the appearance is not pathognomonic we believe that, if the patient is cyanosed and the lung vessels full, the finding of a large left atrium even in the absence of any other abnormality should suggest the possibility of tricuspid atresia.

Explanation of the square heart. The cardiac apex can be elevated and rounded by enlargement of either ventricle (Fig. 6) but perhaps left ventricular hypertrophy is more liable to affect the upper part of the left lower segment. However, we do not believe that left ventricular enlargement alone is sufficient to account for the square heart which is such a characteristic feature in some cases of tricuspid atresia, especially when the lungs are oligæmic.

In 1951 Janker and Hallerbach, using ciné-angiocardiography, pointed out that in tricuspid atresia the left atrial appendix usually showed clearly, whereas it was rarely visible in Fallot's tetralogy. In one of our patients (Fig. 5A), the angular part of the left heart border was formed by a distinctly demarcated segment and angiocardiograms showed the prominence to be due to the left atrial appendix (Fig. 7A). There were similar findings in another child, and we suggest that the square configuration of the heart is due to a prominent left atrial appendix below a concave pulmonary segment.

In the left oblique view the square shape depends on a bulge in the upper part of the posterior border. Angiocardiograms show that this prominence also is atrial and that the chamber seems to be displaced upwards.

Curiously enough, despite this evidence of left atrial prominence in two projections, none of the children with a square heart has shown deviation of the osophagus when examined in the right anterior oblique position; such deviation has been confined to those not showing the square configuration. This seems to contradict Schwedel's (1946) rule that the smooth walled atrium enlarges before 
its trabeculated appendix, but the contradiction may be more apparent than real. Janker and
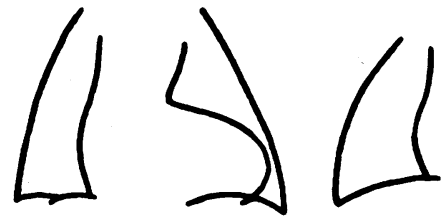

(a)

(a)

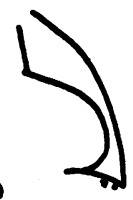

FIG. 6.-The left heart border in right and left ventricular enlargement. (a) Right ventricular enlargement (Fallot's tetralogy). (b) Left ventricular enlargement (chronic hypertension; no cardiac abnormality except left ventricular hypertrophy shown at necropsy). The cardiac apex is elevated and the left lower segment rounded in both infants.

Hallerbach (1951) believe that left ventricular hypertrophy, when associated with a rudimentary right ventricle, may cause cardiac rotation and so make the appendix of the left atrium readily visible. We agree with these observations and believe that the prominence of the left atrial appendix in tricuspid atresia is often due rather to altered anatomical relationships than to the degree of enlargement.

From our analysis we conclude that direct X-ray examination can indicate the diagnosis in a considerable proportion of cases, especially when the lungs are oligæmic. Recognition of the anomaly is much more difficult when they are normal or plethoric.

\section{ANGIOCARDIOGRAPHY}

Seven children were examined by angiocardiography. The main feature in each case was the flow of diodone from the right to the left atrium in the early pictures. Instead of the normal U-shape of the right heart in the frontal position, the two atria formed a continuous band of opacity with a well defined horizontal upper margin that extended from the right heart border across the mid-line towards the left. Meanwhile the position normally occupied by the right ventricular inflow tract, just above the diaphragm to the left of the mid-line, was conspicuously empty (Fig. 7A). Both these features were emphasized by Campbell and Hills (1950).

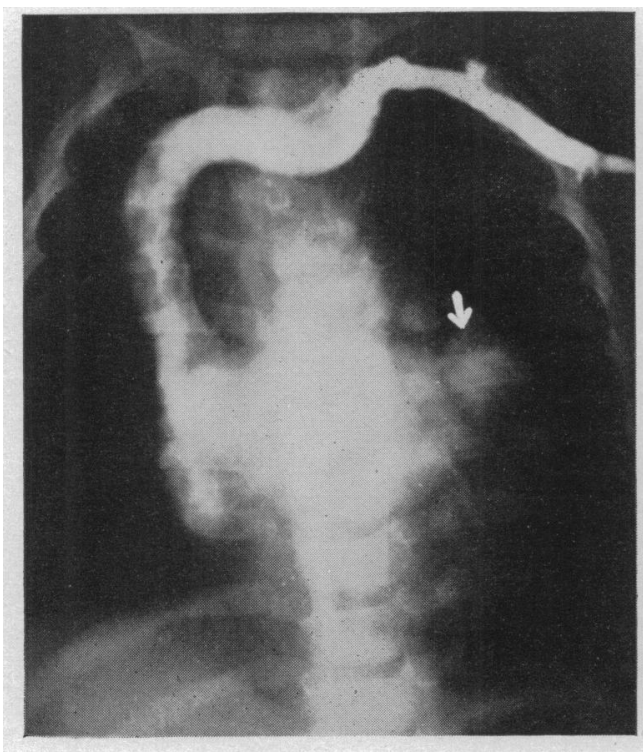

A

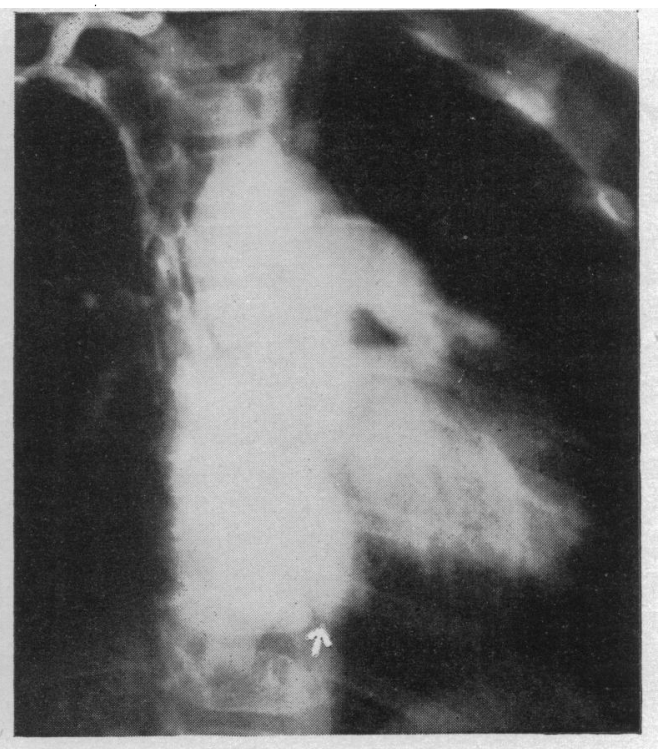

B

FIG. 7.- (A) Early angiocardiogram film, corresponding to Fig. 5. There is a flow of diodone from the right atrium to the left atrium while the area normally occupied by the right ventricular inflow tract is empty. The prominence of the left heart border in the straight radiograph is seen to be due to the left atrial appendix (arrow). (B) Angiocardiogram later in the series. (Not the same child as in Fig. 7A.) From the left atrium diodone has entered the left ventricle and both great vessels have filled immediately (transposition of pulmonary artery only). Later, a rudimentary right ventricle has filled (arrow). 
The left ventricle filled from the left atrium. The rudimentary right ventricle was recognized late in the series on three occasions in the position normally occupied by the right ventricular inflow tract (Fig. 7B).

In four patients the aorta, lying in its normal position, filled immediately from the left ventricle. In three of these filling of the main pulmonary arteries was delayed or not seen, and we concluded that the arteries were arising from a rudimentary right ventricle. The fourth child showed immediate filling from the left ventricle of both the aorta and the main pulmonary artery, indicating transposition of the pulmonary trunk only. All four had poor filling of the peripheral lung vessels, corresponding to the oligæmic appearance recognized on direct examination.

In the remaining three children aortic filling was delayed, whereas the main pulmonary artery filled immediately from the left ventricle. The pulmonary blood flow, estimated by the filling of the peripheral parts of the pulmonary arterial tree, was good and corresponded to an appearance of normal or increased lung vascularity on direct examination. We concluded that these children had complete transposition of the great vessels.

Angiocardiography proved useful to confirm the diagnosis; it gave information about the size of the atrial defect and-sometimes by inference-about the origin of the great vessels; it gave potentially valuable pre-operative evidence concerning the size and position of the pulmonary arteries.

\section{Prognosis AND Treatment}

Our findings are essentially the same as those of previous workers. If the lungs are oligæmic it is likely that the pulmonary artery is arising from the rudimentary right ventricle or, if transposed to the left ventricle, that it is stenosed. In either case death is likely to occur in infancy. Four of our five patients with pulmonary stenosis died early and two of these infants had transposition. When a pulmonary artery of normal calibre is transposed to the left ventricle, the pulmonary blood flow is increased and the prognosis is much more favourable (Hedinger, 1915). This state of affairs is suggested radiologically by congested lungs, and in such cases it is pointless to try to improve the condition by surgical methods designed to increase pulmonary flow.

We do not accept Gasul's (1950) suggestion that, in tricuspid atresia, operation should be confined to those infants who have pulmonary stenosis without transposition. Discussing the treatment of patients with complete transposition of the great vessels (without tricuspid atresia) we suggested that associated pulmonary stenosis improved the prospects of a successful anastomotic operation (Astley and Parsons, 1952). Much the same arguments apply to children with transposition, pulmonary stenosis, and tricuspid atresia. Unsaturated blood entering the right atrium flows to the left atrium and thence, mixed with oxygenated blood returning in small quantity from the lungs, enters the left ventricle. Blood escapes with difficulty through the stenosed, transposed pulmonary artery to the lungs, but passes more readily through the ventricular septal defect to the rudimentary right ventricle and aorta. By anastomosing an aortic branch to a pulmonary artery the flow of blood to the lungs is increased and consequently more oxygenated blood returns to the heart. The work of the left ventricle and the volume of blood passing through right ventricle, aorta, and coronary arteries is but little changed. However, the blood is better oxygenated so that all organs supplied by the aorta must benefit including, of course, the myocardium.

We therefore consider that, in tricuspid atresia, providing the atrial septal defect is large enough to allow a good flow of blood from right to left, demonstration of pulmonary oligæmia is the sole criterion needed before advising thoracotomy. In view of the poor prognosis, operation should be performed as soon as possible after confirmation of the diagnosis and, since the vast majority of patients are likely to be infants, Potts's operation is to be preferred to the Blalock-Taussig anastomosis. Results of operation vary. The immediate mortality is higher than in pulmonary stenosis. After successful operation great improvement is to be expected, but, because there is only one functioning ventricle, it is unlikely ever to be so remarkable as that obtained in Fallot's tetralogy. 


\section{SUMMARY}

Fifteen cases of tricuspid atresia and one of congenital tricuspid stenosis have been examined. The combination of distended, pulsating neck veins with a cardiogram showing left axis deviation is almost diagnostic, but exceptions are noted. Methods of differentiating associated cardiac malformation are considered in view of the influence of these factors on diagnostic features and on prognosis. Radiological appearances are reviewed and fresh diagnostic criteria are suggested. Results of angiocardiography are given and the selection of patients for operation is discussed.

\section{REFERENCES}

Astley, R., and Parsons, C. G. (1952). Brit. Heart J., 14, 13.

Brown, J. W. (1950). Congenital Heart Disease. 2nd ed., Staples, London.

Campbell, M., and Hills, T. H. (1950). Brit. Heart J., 12, 83.

Cooley, R. N., Sloan, R. D., Hanlon, C. R., and Bahnson, H. T. (1950). Radiology, 54, 848.

Donzelot, E., Durand, M., Métianu, C., and Vlad, P. (1950). Arch. Mal. Coeur, 43, 577.

Edwards, J. E., and Burchell, H. B. (1949). Med. Clin. North America, 33, 1177.

Eek, S. (1949). In Mannheimer's Morbus Caeruleus. Karger, Basle.

Gasul, B. M., Fell, E. H., Marino, J. J., and Davis, C. B. (1949). Amer. J. Dis. Child., 78, 16.

- - Mavrellis, W., and Casas, R. (1950). Pediatrics, 6, 862.

Hedinger, E. (1915). Centralbl. Allg. Path. Anat., 26, 529.

Janker, R., and Hallerbach, H. (1951). Fortschr. Gebiete Röntgenstrahlen, 75, 393.

Kroop, I. G. (1951). Amer. Heart J., 41, 549. and Grishman, A. (1950). J. Pediat., 37, 231.

Roesler, H. (1943). Clinical Roentgenology of the Cardiovascular System. 2nd ed., Thomas, Springfield.

Schwedel, J. B. (1946). Clinical Roentgenology of the Heart. Hoeber, New York.

Snow, P. J. D. (1952). Brit. Heart J., 14, 387.

Taussig, H. B. (1936). Bull. Johns Hopkins Hosp., 59, 435. (1947). Congenital Malformations of the Heart. Commonwealth Fund, New York.

Wittenborg, M. H., Nauhauser, E. B. D., and Sprunt, W. H. (1951). Amer. J. Roentgenol., 66, 712. 